Studia i materiały z dziedzictwa kulturowego Torunia i regionu, t. 1: STARE I NOWE DZIEDZICTWO TORUNIA,

Toruń 2013

http://dx.doi.org/10.12775/SiMzDzKTiR_T1.2013.013

Zbigniew Nawrocki

(TORUŃ)

\title{
Kilka nie od razu rozpoznanych elementów wyposażenia kamienic toruńskich
}

Niemal każda położona w obrębie toruńskiej Starówki kamienica, poddawana analizie zabytkoznawczej i badaniom konserwatorskim, przynosi nowe informacje na temat kształtu, wyposażenia czy wystroju, charakterystycznego dla kolejnych etapów jej rozwoju, służące jako podbudowa dla wniosków ogólnych na temat toruńskich domów mieszczańskich. W kamienicach było - i w dalszym ciągu jest - wiele elementów wyposażenia o niezidentyfikowanym przeznaczeniu. Nie od razu na przykład rozpoznawano piece do grzania ciepłym powietrzem, piwniczne schody, korytarze na podwórze, umywalki.

W wielu piwnicach spotyka się nieduże, murowane, sklepione kolebkowo pomieszczenia. Przypuszczałem, że mogły to być miejsca, przeznaczone do przechowywania żywności, a znajdujący się w sklepieniu otwór mógł pełnić funkcje wentylacyjne. Problem w analizie stanowiły drzwi do tych pomieszczeń, gdyż nawet jeśli były zachowane, to osadzone we wtórnych ościeżach. Jakie było przeznaczenie tych pomieszczeń - okazało się w roku 1972, podczas robót w kamienicy przy ul. Szczytnej nr 15, w której przypadku wyrażono zgodę, żeby w przemurowaniach zagadkowego, wbudowanego w narożu piwnicy filara poprzedzonego komorą, wbudować skrzynkę z instalacjami elektrycznymi. Gdy robotnik z rozmachem wbijał w mur przecinak, ten nagle wpadł do jego środka. Okazało się, że w tajemniczym filarze znajduje się sklepiona komora z ceglanym rusztem i leżącymi na nim kamieniami. Był to zatem piec, służący do ogrzania ciepłym powietrzem izby na parterze (il. 1). Ten przypadek pozwala zinterpretować funkcję wszystkich innych podobnych komór.

W literaturze i w ogólnym przekonaniu przyjmowano, że wejście do gotyckiej piwnicy prowadziło z ulicy. O tym, że mogło prowadzić także z dużej sieni, wiadomo już było w latach 60. XX wieku, przy okazji prac przy ul. Szczytnej 2/4 - kwestionowano jednak jego autentyczność. Udało się ją podeprzeć analogią dopiero podczas prac w kamienicy przy ul. Łaziennej nr 22 w latach 90. XX wieku, gdzie odnaleziono schody z dwóch faz historycznych (il. 2 i 3). Przykład ten potwierdził, że w niektórych kamienicach toruńskich do piwnicy wchodziło się także z dużej sieni.

Uważano (a niektórzy uważają także obecnie), że z dużej sieni na podwórze musiał pro- 
wadzić korytarz, wydzielony z boku izby tylnej. Że tak nie było, wiadomo już od czasu prac w kamienicach przy ul. Kopernika numery od 15 do 21, prowadzonych w początku lat siedemdziesiątych XX wieku. W Toruniu w najstarszych kamienicach dwutraktowych na podwórze z dużej sieni szło się mianowicie przez izbę tylną, a wydzielony w niej korytarz spopularyzowany został dopiero od XV wieku. Najlepszym przykładem takiego późniejszego wydzielenia korytarza jest kamienica przy ul. Łaziennej nr 22 (il. 4).

Kolejnym problemem, wartym uwagi, wydają się popularne w kamienicach toruńskich wnęki. Występowanie takich różnej wielkości wnęk w murach gotyckich kamienic traktuje się jako rzecz normalną, niezależnie od tego, czy były to wnętrza mieszkalne, czy magazynowe. Jedne z nich sięgają do stropu, inne są małe, mogą mierzyć np. 30 x $30 \mathrm{~cm}$. Najpopularniejsze są wnęki o przeciętnych wymiarach około $60 \mathrm{~cm}$ szerokości, 1 metra wysokości i głębokie na 30-45 cm. Zwykle umieszczone są mniej więcej $70 \mathrm{~cm}$ nad podłogą. Jedne były używane jako zamykane drzwiczkami szafki, jak np. w kamienicy przy ul. Kopernika 15, $\mathrm{w}$ izdebce $\mathrm{w}$ trakcie frontowym na pierwszym piętrze, inne posiadały deskowe półki, po których mogły pozostawać w ściankach bocznych widoczne bruzdy. Nie znano natomiast wyjaśnienia, dlaczego niektóre z nich umieszczone są w sklepionych blendach o tej samej, co wnęka szerokości albo szerszych, ale zawsze wyższych.

O możliwości przeznaczenia niektórych z nich do innej funkcji, niż szafkowa, dowiedziałem się podczas prac konserwatorsko-adaptacyjnych kamienicy przy ul. Żeglarskiej 13 w Toruniu. Kamienicę tę w początku lat 90-tych XX w. zakupił PZU-Życie z przeznaczeniem na własną siedzibę z pomieszczeniami dla administracji i obsługi klientów. Kamienica w momencie zakupu była wielorodzinną, o klasycystycznej elewacji, z widocznymi spod tynku skutego na fasadzie elementami gotyckimi, przypominającymi detale elewacji toruńskiego ratusza. Rozpoznanie zabytkoznawcze wnętrza budowli wykazało, że z okresu gotyckiego zachowany jest strop dużej sieni i trzy kondygnacje tylnego traktu. Nie zachowała się kondygnacja strychowa z obydwoma szczytami. Podobieństwo opracowania elewacji do elewacji gotyckiego ratusza staromiejskiego każe umieścić jej czas budowy około 1400 roku.

Te cechy spowodowały, że w latach 70. XX w. nie została przebudowana na wielorodzinną. Zaproponowałem Inwestorowi PZU-Życie dążenie do przywrócenia wyglądu budynku i układu pomieszczeń z okresu gotyckiego, a w przypadku odkrycia do tej pory zakrytych elementów wystroju i wyposażenia, także możliwość aktualizacji ustaleń. Należy podkreślić, że Inwestor przez cały czas trwania prac nie wycofał się ze wstępnych założeń, przyjętych podczas rozmów wstępnych, gdy wiele spraw było jeszcze niepewnych. Tolerował wprowadzanie poprawek, których było sporo, gdyż kamienica okazała się skarbnicą nowości, zarówno jeśli chodzi o układ przestrzenny, jak i wyposażenie. Zachowała się tu największa, zgromadzona w jednej kamienicy, liczba kominków; w piwnicy przemieszczono piec do ogrzewania ciepłym powietrzem, były schody z dużej sieni do piwnicy. Przede wszystkim jednak okazało się, że wnęki w tym budynku niekoniecznie musiały służyć jako szafki w niektórych były urządzone umywalki. Funkcję taką jednoznacznie stwierdziłem w przypadku wnęki, znajdującej się w wiszącej izbie w dużej sieni w południowym murze sąsiedzkim, w pobliżu muru frontowego (il. 5).

Wnękę tę odkryto niestety dopiero w końcowym etapie prac, gdy inne wnęki już zostały 
„uporządkowane”. Po usunięciu zamurowania okazało się, że jest to wnęka o standardowym kształcie, ale z wbudowaną - wykonaną ze sztucznego kamienia - płaską misą, posiadającą odpływ, skierowany w stronę ulicy i ze zwisającym ze sklepienia, wydłużonym, obracającym się hakiem, służącym do zawieszenia naczynia - np. z wodą. To odkrycie spowodowało, że poddałem analizie wszystkie wnęki w tej kamienicy. Okazało się, że podobną funkcję miały też wnęki w murach bocznych w pobliżu muru frontowego albo tylnego wszystkich pomieszczeń mieszkalnych. W trakcie frontowym są to wnęki o kształcie „podstawowym”, jak wyżej opisana, a w izbach traktu tylnego - umieszczone w sklepionych ostrołukowo blendach. W izbie tylnej na piętrze w blendzie nad wnęką zachowały się relikty malowidła, przedstawiającego Zwiastowanie NMP (il. 6). Malowidło to zostało poddane tylko konserwacji zachowawczej. Przez analogię np. do izby na piętrze traktu tylnego w budynku przy ul. św. Katarzyny 9, albo dawnej gildii przy ul. Żeglarskiej $5 \mathrm{w}$ Toruniu można wnioskować, że w tamtym czasie malowidłami o tematyce religijnej były pokryte wszystkie ściany tej izby. Izba na piętrze traktu tylnego była z reguły najbardziej elegancka, nazywana „świetlicą” albo „salonem”. Zapewne nieprzypadkowo wnęka umywalkowa znalazła się w obrazie Roberta Campin (il. 7) przedstawiającym Zwiastowanie NMP - umywalka i umieszczone w niej przedmioty symbolizowały czystość Matki Bożej. Być może w związku z tą symboliką w toruńskiej kamienicy, w miejscu służącym do utrzymania czystości, przedstawiono właśnie scenę Zwiastowania. Umywalka, podobna do wyżej omówionej, znajduje się w omawianej kamienicy także w tylnej izbie parteru, przy drzwiach prowadzących na podwórze. Z kolei umywalki podobne do tej w izbie wiszącej, znajdują się w obu pomieszczeniach frontowych w kondygnacji nad dużą sienią. Razem jest tam zatem pięć umywalek. Jak do tej pory jest to największa liczba umywalek, odkryta w jednym budynku (il. 8 i 9) przez minionych kilkanaście lat.

Wnęki umywalkowe w kamienicy przy ul. Żeglarskiej 13 nie są jednak jedynymi w Toruniu, które można zinterpretować jako umywalki. Podobnie, jak w izbach jej obu kondygnacji traktu tylnego, wnęki umywalkowe znajdują się w pomieszczeniach obu kondygnacji traktu tylnego kamienicy przy ul. Królowej Jadwigi nr 9 (il. 10), gdzie w izbie na parterze wnęka biegnie przez całą wysokość ściany i ma głębokość $45 \mathrm{~cm}$. Naczynie z wodą wisiało tam, podwieszone do drewnianej półki. Na piętrze wnęka umywalkowa umieszczona jest w wysokiej blendzie, a w jej tle namalowano postać św. Jakuba St. w odpornej na wodę technice al fresco ${ }^{1}$. W kamienicy przy ul. Łaziennej nr 16 wnęka umywalkowa znajduje się z kolei w sieni w murze bocznym od strony ul. Ciasnej, w pobliżu muru międzytraktowego (il. 11). Jest umieszczona w wysokiej, ostrołukowej blendzie. Zamknięta jest deską, do której było podwieszone naczynie $\mathrm{z}$ wodą. Jak do tej pory jest to jedyny znany przypadek umywalki, funkcjonującej w dużej sieni.

Dwie wnęki jednoznacznie umywalkowe znaleziono również podczas prac w roku 2012. Niemal równocześnie Ewelina Nawrocka odkryła umywalkę w kamienicy przy Rynku Staromiejskim 4 (il. 12 i 13) a Jolanta Korcz - w kamienicy przy ul. Żeglarskiej 7 (il. 14). Umywalka w kamienicy przy Rynku Staromiejskim nr 4 znajduje się na parterze traktu tylnego,

1 Informację zawdzięczam Elżbiecie Rogozińskiej. 
w pobliżu muru tylnego. Charakteryzuje się ona tym, że poniżej przesklepienia posiada drewnianą półkę $\mathrm{z}$ otworem, przeznaczonym zapewne na umieszczenie $\mathrm{w}$ nim haka, na którym wieszano naczynie $\mathrm{z}$ wodą. Po misie i odpływie w stronę podwórza pozostały tylko relikty. W kamienicy przy ul. Żeglarskiej 7 wnęka umywalkowa została odkryta na piętrze w izbie tylnej w murze bocznym od strony ul. Rabiańskiej, w pobliżu muru międzytraktowego. W dobrym stanie zachowana jest płaska misa ze sztucznego kamienia, stanowiąca dno wnęki, pochylona w stronę otworu, wyprowadzonego do ulicy. W sklepieniu niszy zachowała się pozostałość haka. Obecnie umywalka ta znajduje się tuż nad podłogą, choć powinna mieścić się na wysokości ok. $70 \mathrm{~cm}$. Jej dolna część zasłonięta jest kamienną płytą, prawdopodobnie chroniąca niegdyś podłogę przed rozpryskiwaną wodą. Świadczy to o tym, że używana była jeszcze przynajmniej w XVI wieku, czyli w czasie, gdy zgodnie z duchem epoki przebudowano wnętrze i podniesiono do dzisiejszego poziomu strop między parterem i piętrem traktu tylnego. W osi umywalki na piętrze znajduje się także umywalka na parterze, umieszczona w ostrołukowo sklepionej blendzie. Ta dolna wnęka została zidentyfikowana jako umywalka dużo wcześniej, to jest po odkryciach w kamienicy przy ul. Żeglarskiej 13.

Warto w tym kontekście wspomnieć o szczególnej analogii na terenie średniowiecznego Torunia - wnęce o przeznaczeniu liturgicznym, zachowanej w masywie wieżowym kościoła Świętojańskiego, budowanym w latach 1407-1433. Budowa tej wieży o dziesięć lat wyprzedziła rozbudowę dzisiejszej hali kościoła. Przypuszcza się, że wieża ma obecnie 3/4 zaplanowanej wysokości, czyli trzy z zaplanowanych czterech kondygnacji. Kondygnacja dolna, przesklepiona sklepieniem gwieździstym, jest kruchtą otwartą na całej wysokości do nawy głównej. Kondygnacja druga, też przykryta sklepieniem gwieździstym, była - podobnie jak kruchta - otwarta na całej wysokości ostrołukową arkadą do nawy głównej. Sklepienie tej kondygnacji w wieży pokryte jest dekoracją malarską, podobną do dekoracji malarskiej na sklepieniach naw kościoła; sklepienie arkady jest pokryte dekoracją malarską znacznie bogatszą. Obecnie w arkadę jest wbudowany mur ceglany w wątku polskim, zbudowany prawdopodobnie w trzech etapach, oddzielający drugą kondygnację wieży od nawy głównej kościoła, późniejszy od polichromii sklepienia. Kondygnacja wieży na całej wysokości od zachodu oświetlona jest dużym oknem. W zachodniej części muru południowego, nad posadzką znajduje się wnęka, wysoka na $170 \mathrm{~cm}$, szeroka na $70 \mathrm{~cm}$, głęboka na $45 \mathrm{~cm}$ i w niej - na wysokości $70 \mathrm{~cm}$ - znajduje się następna wnęka o głębokości $45 \mathrm{~cm}$. Obie zamknięte są łukiem odcinkowym (il. 15 i 16). U dołu drugiej wnęki zachowane są relikty wykonanej ze sztucznego kamienia misy, zaopatrzonej w odpływ w dół do muru. Wnęka ta podobna jest do wyżej omówionych wnęk umywalkowych w toruńskich kamienicach. Mogła to być piscina - służąca do puryfikacji naczyń liturgicznych, lub lawaterz służący jako umywalnia kapłańska do obmycia rąk podczas mszy św. W południowym murze bocznym tej kondygnacji (il. 15), obok drzwi, znajduje się blisko metrowej szerokości wnęka - zapewne szafkowa, która mogła służyć do przechowywania paramentów. Nasuwa się tu wniosek, że druga kondygnacja wieży była kaplicą otwartą do nawy głównej. Mogła to być kaplica poświęcona jednemu ze świętych Janów - patronów kościoła. Duże okno, oświetlające teraz tylko drugą kondygnację wieży, pierwotnie oświetlało nawę główną. 
Nie wymieniam w tym artykule wszystkich toruńskich kamienic posiadających wnęki, które mogły być umywalkami. Mam świadomość, że jest ich wiele więcej, co zachęca do dalszego ich rozpoznawania.

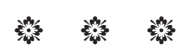

\section{Not at once recognised elements of fittings of tenement houses in Toruń}

In the tenement houses in Torun there always have been many elements of fittings of unidentified purpose. For example, the purpose of small vault premises in the tenement house at 15, Szczytna Street became clear in 1972. A grate made of bricks was found under a layer of stones. It was a stove used for heating the rooms situated on the ground floor by warm air. This case has served as the pattern for explaining the purpose of all similar chambers.

Since the renovation works in the tenement houses at 2, Szczytna Street and 22, Eazienna Street it has been known that cellars could be approached not only from a street, but also from a big hall. By the examples of the tenement houses at 15 and 21, Kopernik street it appeared that in the oldest houses with two passageways there was a passage from the big hall to the courtyard led through the back chamber, or later, since $15^{\text {th }}$ century, by a corridor separated from the back chamber.

Niches of different sizes can be found in Gothic walls regardless of their purpose-either for habitation, or storing. In the tenement house at 13, Żeglarska Street it became clear there were wash-stands arranged in certain niches. In the hanging room it is a niche of the common shape, yet equipped with a flat stone basin with a drain directed into the street and a long, revolving hook. Such was the function of niches in all housing chambers situated in side walls near the front or back wall of the house. In the blind window above the niche in the back room on the first floor relicts of a painting showing The Annunciation have been preserved. A similar niche can be found in the van den Verden's painting showing The Annunciation.

In the tenement house at 16, Łazienna Street a wash-stand niche is situated in the hall's side wall of the side of the Ciasna Street. It has been the only known case of a wash-stand in a big hall so far.

In 2012 such niches were uncovered in the tenement houses at 3, Rynek Staromiejski and 7, Zeglarska Street. The second floor of the tower of the Cathedral Basilica of St. John the Baptist and St. John the Evangelist was open towards the nave by a sharp-arch arcade (presently closed by a wall) and enlightened from the west through a window situated in a niche. At the southern wall of the niche above the floor there is a niche $170 \mathrm{~cm}$ high and then, the next niche $45 \mathrm{~cm}$ deep with preserved relicts of a bowl made of an artificial stone. It is similar to wash-stand niches in tenement houses. It could be a lavabo (aquamanile), functioning as a wash-room for priests. It can be assumed the second floor of the tower was a chapel open towards the church's nave. 


\section{SPIS ILUSTRACJI:}

1. Toruń, kamienica przy ul. Szczytnej 15. Piwnica, wnętrze pieca do grzania ciepłym powietrzem, fot. Z. Nawrocki (1972 r.)

2. Toruń, kamienica przy ul. Łaziennej 22. Schody „1” z traktu tylnego piwnicy do dużej sieni przy murze pd. Wejście częściowo zasłonięte słupem konstrukcyjnym, fot. Z. Nawrocki (2012 r.)

3. Toruń, kamienica przy ul. Łaziennej 22. Schody „2” z traktu tylnego piwnicy do dużej sieni, w części środkowej muru międzytraktowego, fot. Z. Nawrocki (2012 r.)

4. Toruń, kamienica przy ul. Łaziennej 22. Korytarz z dużej sieni na podwórze wydzielony w trakcie tylnym w XV w, fot. Z. Nawrocki (1997 r.)

5. Toruń, kamienica przy ul. Żeglarskiej 13. Wnęka umywalkowa w izbie wiszącej, fot. Z. Nawrocki (1995 r.)

6. Toruń, kamienica przy ul. Żeglarskiej 13. Wnęka umywalkowa, I piętro, trakt tylny, fot. Z. Nawrocki (2012 r.)

7. Robert Campin, Tryptyk Mérode, fot. wg: Sztuka Gotyku, red. Rolf Toman, Köln 1998.

8. Toruń, kamienica przy ul. Żeglarskiej 13. Przekrój podłużny, widok na mur południowy, kolor czerwony - wnęka umywalkowa, fot. Z. Nawrocki

9. Toruń, kamienica przy ul. Żeglarskiej 13. Rzut, I piętro, kolor czerwony - wnęka umywalkowa, fot. Z. Nawrocki

10.Toruń, kamienica przy Królowej Jadwigi 9. Przekrój podłużny, mur południowy, kolor czerwony - wnęka umywalkowa, fot. Z. Nawrocki

11. Toruń, kamienica przy ul. Łaziennej 16. Wnęka umywalkowa w dużej sieni, fot. Z. Nawrocki (2012 r.)

12.Toruń, kamienica przy Rynku Staromiejskim 4. Wnęka umywalkowa w trakcie tylnym, fot. Z. Nawrocki (2012 r.)

13.Toruń, kamienica przy Rynku Staromiejskim 4. Wnęka umywalkowa w trakcie tylnym, półka z otworem, fot. Z. Nawrocki (2012 r.)

14.Toruń, kamienica przy ul. Żeglarskiej 7. Wnęka umywalkowa w trakcie tylnym na I piętrze, fot. Z. Nawrocki (2012 r.)

15.Toruń, katedra (dawna fara) pw. św. Jana Chrzciciela i św. Jana Ewangelisty. Wieża, druga kondygnacja, widok muru południowego, u dołu z prawej strony lawaterz, fot. Z. Nawrocki (2012 r.)

16.Toruń, katedra (dawna fara) pw. św. Jana Chrzciciela i św. Jana Ewangelisty. Wieża, druga kondygnacja, lawaterz, fot. Z. Nawrocki (2012 r.) 


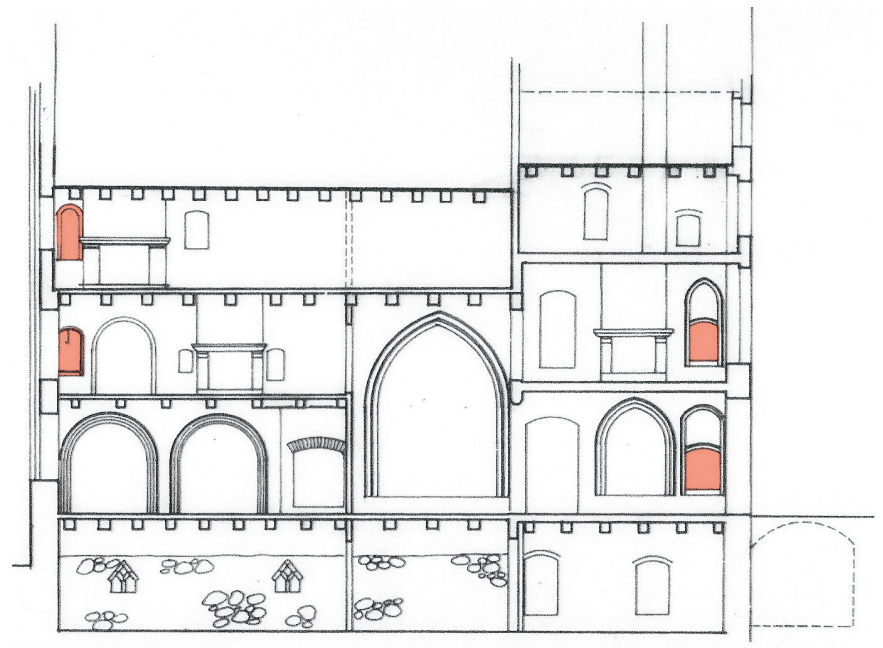

Il. 8 Toruń, kamienica przy ul. Żeglarskiej 13. Przekrój podłużny, widok na mur południowy, kolor czerwony - wnęka umywalkowa, fot. Z. Nawrocki

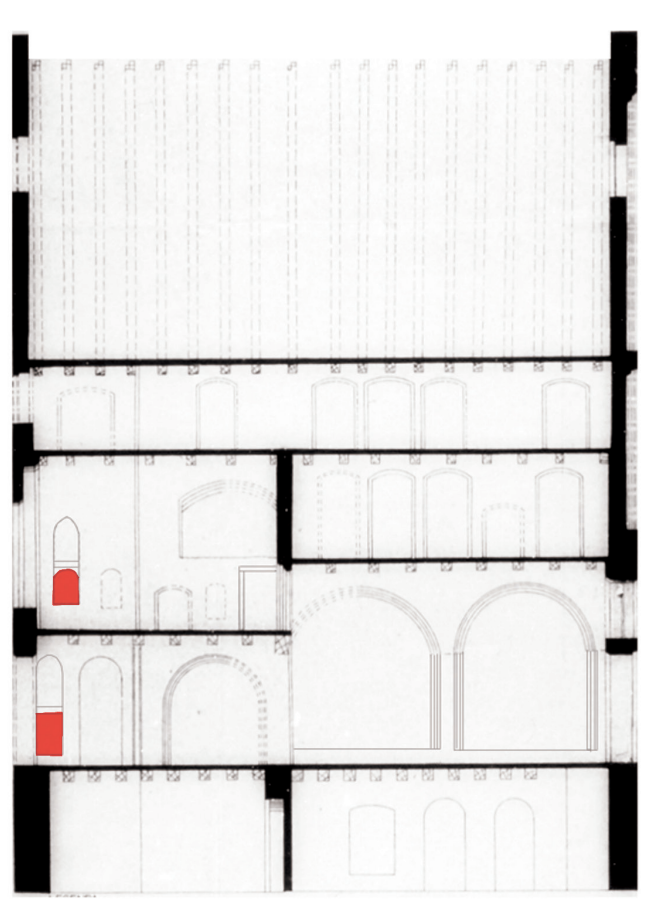

Il. 9 Toruń, kamienica przy ul. Żeglarskiej 13. Rzut, I piętro, kolor czerwony - wnęka umywalkowa, fot. Z. nawrocki

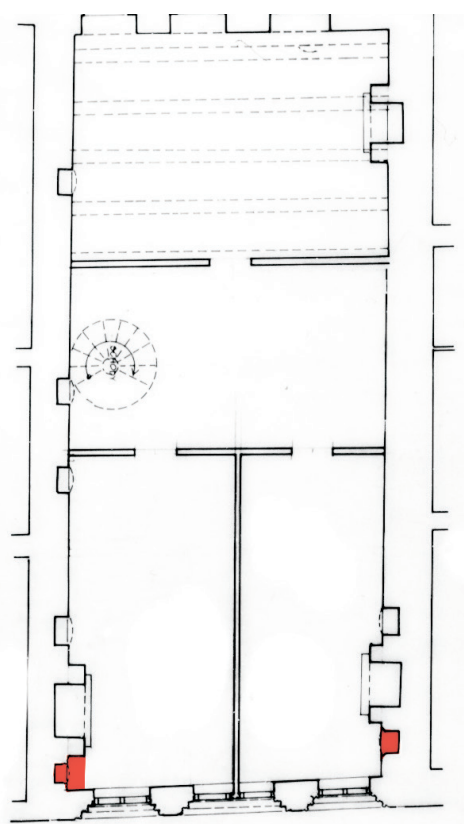

Il. 10 Toruń, kamienica przy Królowej Jadwigi 9. Przekrój podłużny, mur południowy, kolor czerwony - wnęka umywalkowa, fot. Z. Nawrocki 


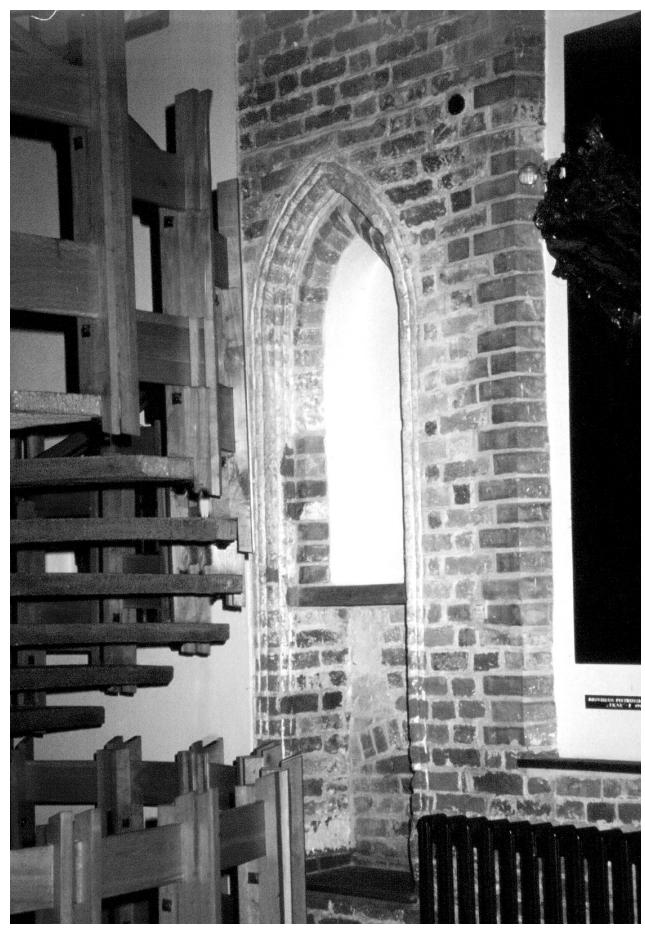

Il. 11 Toruń, kamienica przy ul. Łaziennej 16. Wnęka umywalkowa w dużej sieni, fot. Z. Nawrocki (2012 r.)

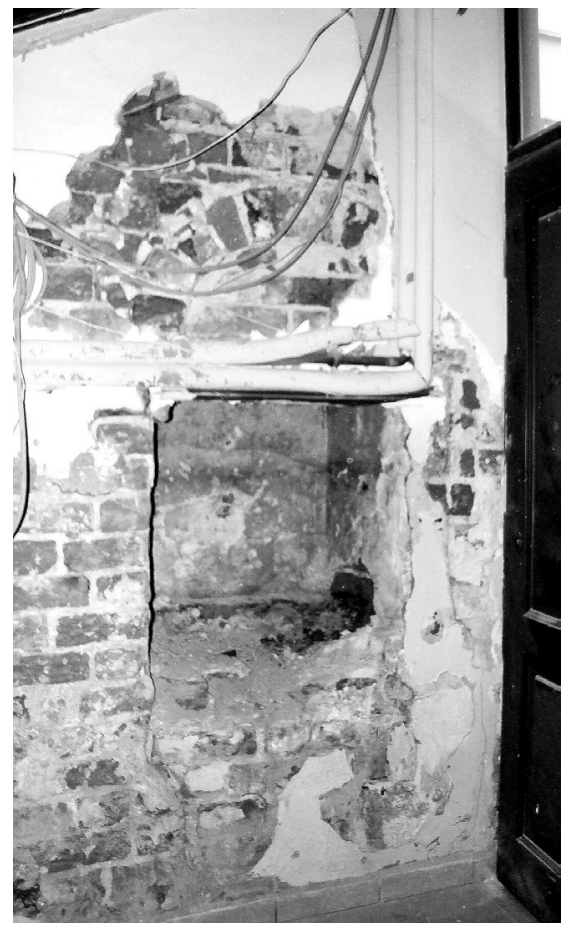

Il. 12 Toruń, kamienica przy Rynku Staromiejskim 4. Wnęka umywalkowa w trakcie tylnym, fot. Z. Nawrocki (2012 r.)

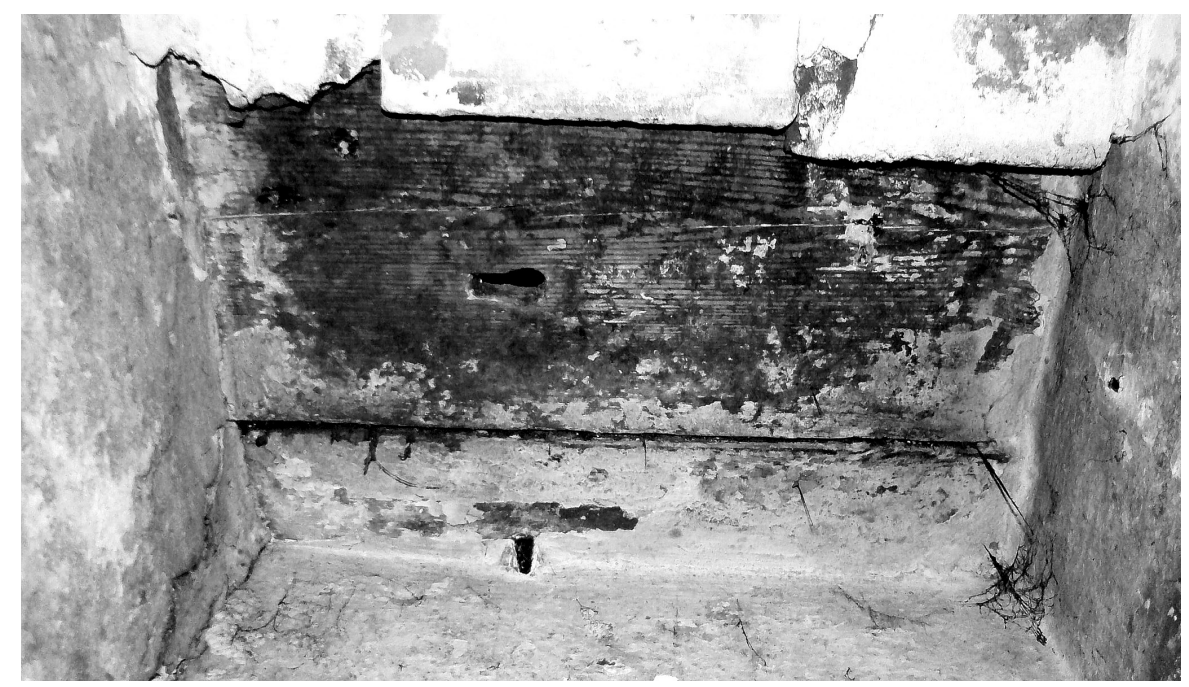

Il. 13 Toruń, kamienica przy Rynku Staromiejskim 4. Wnęka umywalkowa w trakcie tylnym, półka z otworem, fot. Z. Nawrocki (2012 r.) 


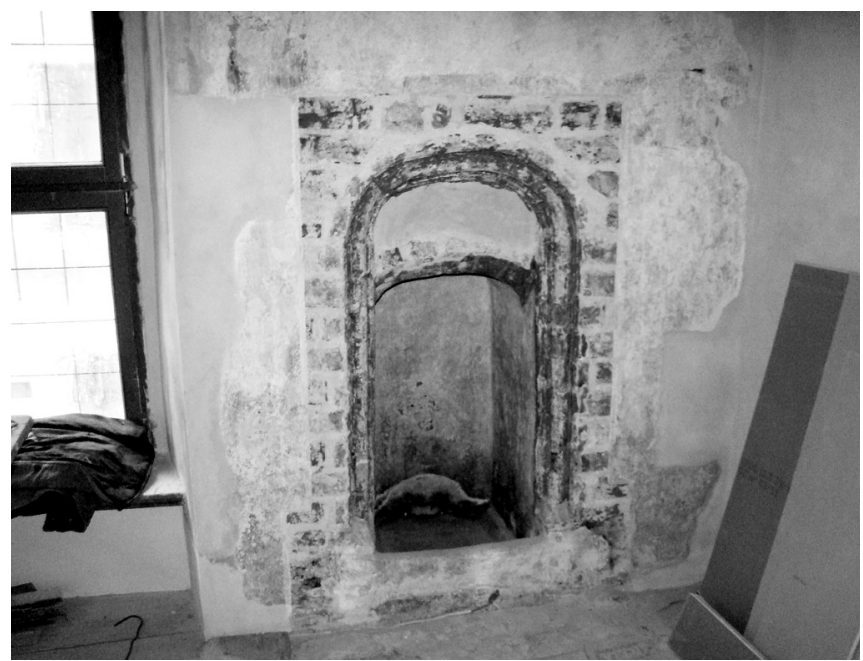

Il. 14 Toruń, kamienica przy ul. Żeglarskiej 7. Wnęka umywalkowa w trakcie tylnym na I piętrze, fot. Z. Nawrocki (2012 r.)

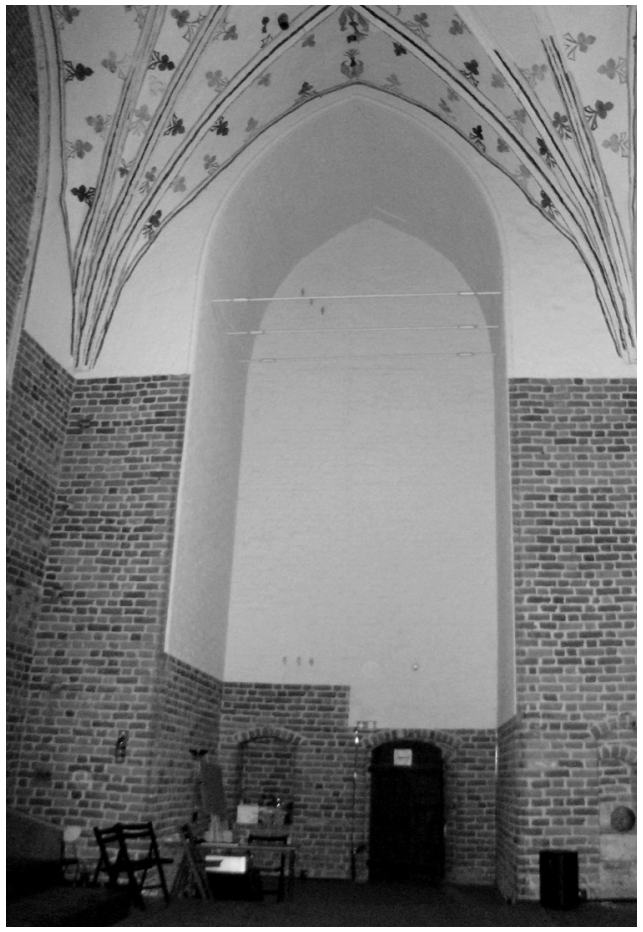

Il. 15 Toruń, katedra (dawna fara) pw. św. Jana Chrzciciela i św. Jana Ewangelisty. Wieża, druga kondygnacja, widok muru południowego, $\mathrm{u}$ dołu $\mathrm{z}$ prawej strony lawaterz, fot. Z. Nawrocki (2012 r.)

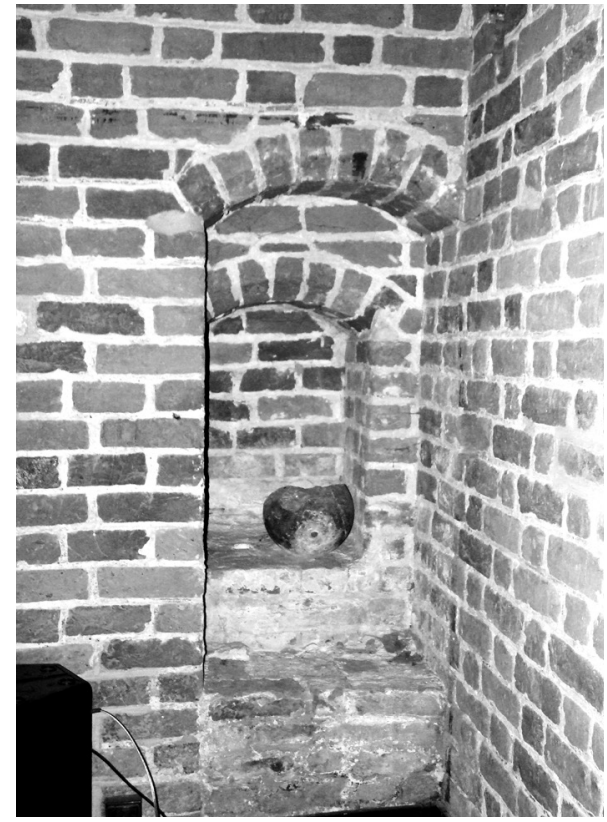

Il. 16 Toruń, katedra (dawna fara) pw. św. Jana Chrzciciela i św. Jana Ewangelisty. Wieża, druga kondygnacja, lawaterz, fot. Z. Nawrocki (2012 r.) 